\title{
Erratum to: Viable but not Culturable Forms of Legionella pneumophila Generated After Heat Shock Treatment are Infectious for Macrophage-like and Alveolar Epithelial cells after Resuscitation on Acanthamoeba polyphaga
}

Thibaut Epalle • Françoise Girardot • Séverine Allegra • Cécile Maurice-Blanc • Olivier Garraud • Serge Riffard

Published online: 27 February 2015

(C) Springer Science+Business Media New York 2015

Erratum to: Microbial Ecology

DOI 10.1007/s00248-014-0470-x

In the original version of this article, our results on A549 cells have not been illustrated. An additional figure (Fig. 6) below confirms the infection of A549 epithelial cells by L. pneumophila VBNC resuscitated through A. polyphaga interaction.

The online version of the original article can be found at http://dx.doi.org/ 10.1007/s00248-014-0470-x.

T. Epalle $\cdot$ F. Girardot $\cdot$ S. Allegra $\cdot$ C. Maurice-Blanc $\cdot$ O. Garraud · S. Riffard $(\bowtie)$

Groupe Immunité des Muqueuses et Agents Pathogènes (GIMAP)

EA 3064, SFR 143, University of Lyon, 42023 Saint-Etienne, France

e-mail: serge.riffard@univ-st-etienne.fr 
A

\section{Red Fluorescence}
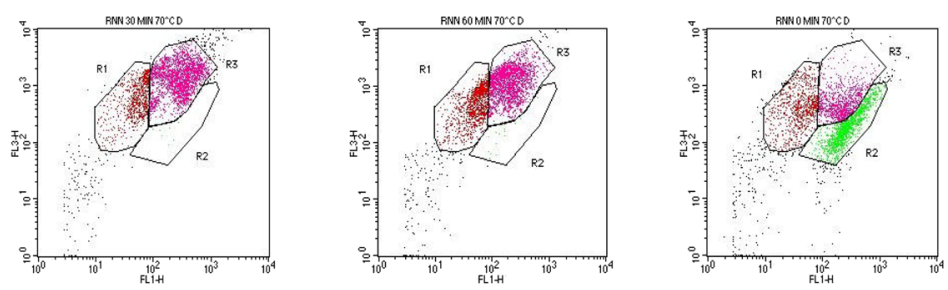

\section{Green Fluorescence}

A
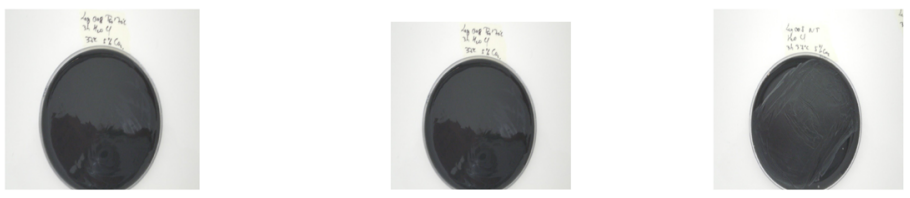

R3

B
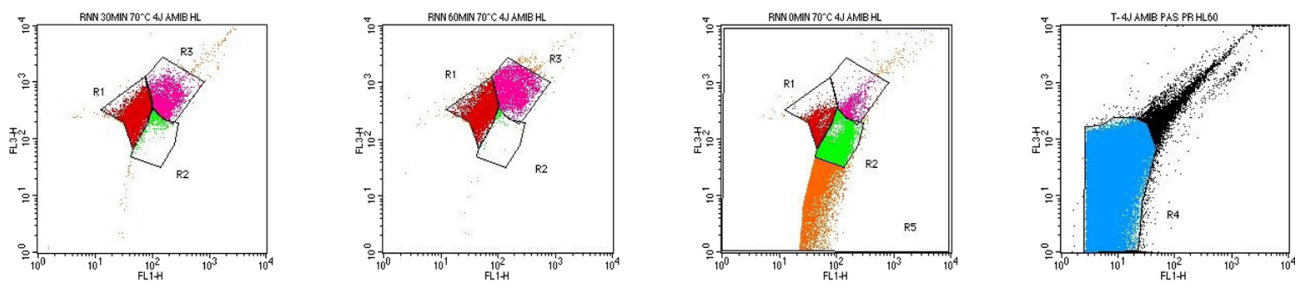

B
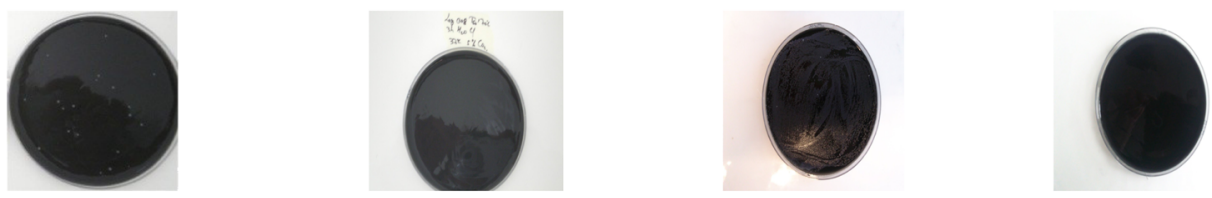

4A. polyphaga

R6

C
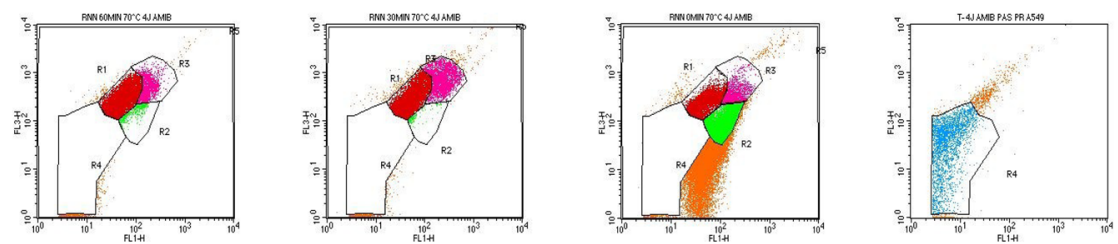

C
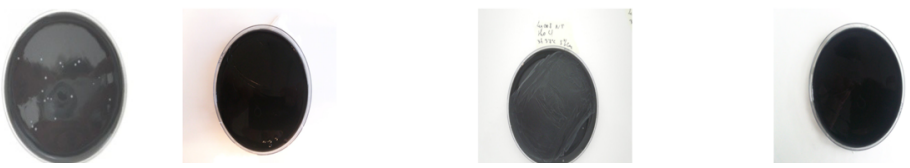

$1\left(30 \min 70^{\circ} \mathrm{C}\right)$

2 (-control)

3 (+control)

5 A549 and A. polyphaga 
4 Fig. 6 Viability and cultivability status of a Lp1-RNN suspension assessed by FCA and culture on BCYE solid medium following heat shock (panel A), following heat shock and after 4 days of culture on amoeba layer (panel B), following heat shock, resuscitation assay on amoeba and co-culture with A549 alveolar epithelial cells (panel C). Heat-shocked suspensions at $70{ }^{\circ} \mathrm{C}$ for $30 \mathrm{~min}$ (1) and $60 \mathrm{~min}$ (2), (3) cells non submitted to heat shock, (4) amoeba control without bacteria, (5) A549 control with A. polyphaga lysate in the absence of bacteria. On cytograms, R1 are DC, R3 are VBNC cells, R2 are VC, R4 is the amoeba population and R6 is A549 population with amoeba lysate. For a better visualization of bacteria, R4 and R6 populations were subtracted from cytograms on panels $\mathrm{B}$ and $\mathrm{C}$ respectively. Numbers of colonies grown on $\mathrm{BCYE}$ are indicated on the corresponding plates. For plates with confluent colonies, the term "overgrowth" is used 